\title{
SPECIAL ISSUE EDITORIAL
}

\section{Attachment in the context of atypical caregiving}

\author{
GLENN I. ROISMAN $^{a}$ AND DANTE CICCHETTI ${ }^{a, b}$ \\ ${ }^{a}$ University of Minnesota; and ${ }^{b}$ University of Rochester Mt. Hope Family Center
}

In early 2015 we were immensely gratified to learn that some of the most creative and productive attachment scholars working in the field today had agreed to offer contributions to what would become this Special Issue of Development and Psychopathology devoted to the topic of Attachment in the Context of Atypical Caregiving. Our primary goals in inviting these manuscripts were the following:

1. to draw attention to recent work that significantly extends, in methodologically rigorous ways, research in this longstanding and generative subdomain of developmental science; and

2. to frame a forward-thinking research agenda that is well positioned to build on the sturdy foundation of prevailing approaches that have characterized attachment research for decades, albeit often in the context of studies of normative or lower risk samples (e.g., Booth-LaForce \& Roisman, 2014; Grossmann, Grossmann, \& Waters, 2005).

As such, alongside arguably more confirmatory, largersample studies in well-established areas-including work examining the long-term legacy of early abuse and neglect for individual differences in adolescent and adult attachment (Raby, Labella, Martin, Carlson, \& Roisman, 2017; Roisman et al., 2017) - we also encouraged the submission of highly innovative efforts, even if more exploratory in nature, for example, empirical reports focused on identifying some of the biological mechanisms supporting the legacy of early attachment experiences (e.g., Mulder et al., 2017; Quevedo et al., 2017; Thijssen et al., 2017) as well as small-scale "proof of concept" interventions (Swain et al., 2017), including those designed to offset risk in especially difficult to reach populations (e.g., Schacht et al., 2017).

Judged against these goals for this Special Issue, we could not be more satisfied with the papers presented in this Special Issue, nor more grateful to the authors who contributed the

Address correspondence and reprint requests to: Glenn I. Roisman or Dante Cicchetti, Institute of Child Development, University of Minnesota, 51 East River Road, Minneapolis, MN 55455; E-mail: roism001@umn.edu or cicchett@umn.edu. studies reported herein. As the reader will no doubt recognize at a glance, the work contained in this Special Issue focuses on a notably wide range of contexts (e.g., institutional rearing; VanTieghem et al., 2017), conditions (e.g., poverty; Kobak, Zajac, Abbott, Zisk, \& Bounoua, 2017), and caregiving behaviors (e.g., maltreatment; Roisman et al., 2017) likely to generate risk in relation to attachment-related individual differences, processes, and disruptions over development. In so doing, the papers presented here collectively not only (a) make significant contributions to advancing the basic science critical to acquiring a better understanding of the consequences of atypical caregiving for attachment-related outcomes but also (b) serve to further realize the translational promise of attachment theory and research to facilitate healthy development in at-risk populations via diverse attachment-related intervention efforts. In short, the papers contained in this Special Issue truly embody a developmental psychopathology perspective on the study of attachment across much of the early life course (Cicchetti, 1984).

By design, the individual reports presented in this Special Issue function as stand-alone contributions to the literature. As such, we expect that many of these papers will serve as important "sign-posts" for subdomains in the study of attachment in definite need of more sustained attention in the coming decades (e.g., the implications for child attachment of parental incarceration; Poehlmann-Tynan, Burnson, Runion, \& Weymouth, 2017). Nonetheless, in the course of coediting the excellent papers in this Special Issue, several themes emerged repeatedly, which we believe merit some attention at the outset. As elaborated on below, these themes included the following:

1. the value of studies of attachment in the context of atypical caregiving for producing methodological insights (e.g., Bailey, Tarabulsy, Moran, Pederson, \& Bento, 2017; Kobak et al., 2017; Martin, Bureau, et al., 2017; Martin, Sturge-Apple, Davies, Romero, \& Buckholz, 2017; Poehlmann-Tynan et al., 2017; Raby, Labella, et al., 2017; Raby, Yarger, et al., 2017);

2. the continued search for biological mechanisms capable of explaining the origins and potentially enduring conse- 
quences of variation in early attachment experiences (Blaze \& Roth, 2017; Fearon et al., 2017; Mulder et al., 2017; Quevedo et al., 2017; Thijssen et al., 2017); and

3. the notable diversity of current attachment-related intervention efforts (Cassidy et al., 2017; Dubois-Comtois et al., 2017; Guild, Toth, Handley, Rogosch, \& Cicchetti, 2017; Handley, Michl-Petzing, Rogosch, Cicchetti, \& Toth, 2017; Humphreys, Nelson, Fox, \& Zeanah, 2017; Schact et al., 2017; Suchman et al., 2017; Swain et al., 2017; Tereno et al., 2017).

\section{Methodological Insights}

Several of the articles contained in this Special Issue provide direct evidence that the study of attachment in the context of atypical caregiving both presents significant methodological challenges and ultimately generates valuable opportunities to acquire insight into the nature of individual differences, especially for lower base rate attachment-related phenomena (e.g., unresolved and preoccupied states of mind). For example, Poehlmann-Tynan et al.'s (2017) study of child attachment in the context of parental incarceration shows clearly that the development of new observational procedures and coding systems is often a prerequisite to studying attachment in highrisk contexts given the extra-scientific constraints that bedevil scholars in this area. Likewise, two other papers contained in this Special Issue describe efforts to design or further validate assessments of the quality of adolescent-parent attachments via direct observations (Kobak et al., 2017; Martin, SturgeApple, et al., 2017). Such methodological contributions to the literature are timely and welcome.

Perhaps even more notable in terms of their methodological significance for attachment research, however, are the studies reported in this Special Issue that address unresolved yet fundamental questions about how individuals vary with respect to how they describe their early experiences with primary caregivers in the context of the Adult Attachment Interview (AAI; George, Kaplan, \& Main, 1984-1996). The canonical view of individual differences in adults' narratives about their childhood experiences is built on two distinct sets of assumptions embedded in the Main and Goldwyn (1984-1998) coding system for the AAI (see Main, Goldwyn, \& Hesse, 2003-2008). The first of these assumptions is that individual differences in adult attachment are best conceptualized as categorically rather than continuously distributed in the population. Arguably even more important, however, is a second set of assumptions regarding the primary axes on which adults vary while talking about their childhood attachment experiences. More specifically, Main and Goldwyn's coding system for the AAI implies that security in adulthood simultaneously reflects the capacity to (a) tell an internally consistent narrative about one's childhood experiences while (b) not becoming emotionally overwrought when talking about those experiences, as reflected either in active or passive preoccupation. In this traditional account that is now well enshrined in the developmental literature, insecurity, by contrast, is conceptualized as taking one of two mutually incompatible organized forms (i.e., dismissing or preoccupied states of mind, but not both).

Prior research based on large, normative-risk cohorts appear inconsistent with both of these sets of assumptions. First, in the only two existing taxometric studies of the AAI that predate this Special Issue (i.e., Fraley \& Roisman, 2014; Roisman, Fraley, \& Belsky, 2007), dismissing states of mind during the AAI (reflected in the normalization of objectively harsh childhood experiences and/or the idealization of childhood experiences with primary caregivers) were demonstrated to be continuously rather than categorically distributed (evidence regarding the taxonicity of preoccupation was indeterminate). Second, all existing factor analytic evidence from a variety of attachment laboratories across the world suggests that, rather than being mutually incompatible, dismissing and preoccupied states of mind appear to be essentially orthogonal (for reviews, see Roisman \& Booth-LaForce, 2014; Martin, Bureau, et al., 2017). Perhaps even more surprising to many attachment scholars, these same factor analyses have demonstrated consistently that indicators of unresolved states of mind (reflecting psychological confusion during the AAI about loss and/or abuse-related experiences specifically) and indicators of preoccupation about early caregiving experiences generally (i.e., passive and/or angry discourse during the AAI) load on a single factor, suggesting that these are not psychologically distinct phenomena, as has been so widely assumed.

Van IJzendoorn and Bakermans-Kranenburg (2014) observed several years ago that a potentially significant limitation of prior taxometric and factor analytic work focused on individual differences in AAI narratives is the lower risk nature of the samples that have been featured in most such psychometric reports (see Roisman, Fraley, \& Booth-LaForce, 2014). At the core of van IJzendoorn and Bakermans-Kranenburg's (2014) critique is the descriptive insight that preoccupied and unresolved states of mind represent relatively low base rate phenomena, especially in typical-risk cohorts, and that any differences between these groups (assuming they are true taxa) might well be obscured in samples that contain relatively few prototypically preoccupied and/or unresolved participants.

It is in this context that several of the studies reported in this Special Issue take on notable significance. Even if we set aside the additional taxometric and confirmatory factor analytic evidence pertinent to the AAI reported by Raby, Yarger, et al. (2017; given that many of the participants in that impressively large sample study were at relatively low risk), Martin, Bureau, et al. (2017) and Raby, Labella, et al. (2017) both present factor analyses demonstrating in higher risk cohorts once again that (a) AAI state of mind scales were most parsimoniously represented by two weakly correlated dismissing and preoccupied state of mind dimensions and (b) unresolved and preoccupied AAI states of mind loaded on a common factor in both samples. Indeed, the Raby, Labella, et al. (2017) report, drawing on data from the landmark Minnesota Longitudinal Study of Risk and Adaptation 
(Sroufe, Egeland, Carlson, \& Collins, 2005), actually extended this two-factor structure to the Current Relationship Interview (Crowell \& Owens, 1996), a close analogue of the AAI focused on experiences with a current romantic partner.

Does the addition to the literature of the factor analyses of the AAI and Current Relationship Interview reported in this Special Issue effectively put an end to debate about the latent structure of individual differences in the ways in which adults discuss their childhood and current attachment experiences? Of course not, but such work definitely does shift the burden of evidence to those who persist in using coding systems in ways that assume that (a) attachment is categorically distributed in adulthood, (b) dismissing and preoccupied states of mind are mutually incompatible, and/or (c) preoccupied and unresolved states of mind represent psychologically distinct attachment phenomena. The empirical support for each of these long-held assertions, at least in regard to evidence derived from taxometric and/or factor analyses of AAI state of mind data drawn from both normative and higher risk cohorts, is largely nonexistent in the developmental literature.

\section{Biological Mechanisms}

Another exciting aspect of the work presented in this Special Issue is the relatively large number of reports emphasizing the potential value of biological markers in informing both (a) the origins of attachment-related variation (e.g., Mulder et al., 2017) and (b) the legacy of early attachment-relevant experiences (Blaze \& Roth, 2017; Fearon et al., 2017; Quevedo et al., 2017; Thijssen et al., 2017). As just a few salient examples, Blaze and Roth (2017) use a rodent model to extend their path-finding work demonstrating the role of early maltreatment in abnormal patterns of methylation in the brain-derived neurotrophic factor $(B d n f)$ gene in the medial prefrontal cortex; and, in the human context, both Thijssen et al. (2017) and Quevedo et al. (2017) make use of functional magnetic resonance imaging to study the ways in which early caregiving experiences are reflected in patterns of neural activation. Such work has the potential to advance behavioral science in part by identifying some of the specific mechanisms that might account for now well-established associations observed between early attachment experiences with primary caregivers and aspects of (mal)adjustment over the early life course (Groh, Fearon, van IJzendoorn, BakermansKranenburg, \& Roisman, in press).

These innovative and diverse papers on biological correlates of attachment-related individual differences surely suggest many more questions than they can possibly answer definitively. For example, only critical replication and extension efforts will ultimately be dispositive regarding which subset of the many, diverse biological systems and methods leveraged in the reports featured here will prove most reliably informative about the legacy of early attachment experiences. Regardless, we anticipate that these studies will serve the field well by providing additional direction for attachment scholarship seeking to understand biological level of analysis mechanisms, an important focus that nonetheless should not be emphasized to the exclusion of a broader search for other relevant developmental mechanisms (e.g., those at the cognitive and behavioral levels of analysis).

\section{Attachment Interventions}

Of the 24 articles in this Special Issue, it is noteworthy that 10 feature the results of attachment-relevant interventions. That so many investigators are now actively engaged in work designed to translate the basic science of attachment in the interest of serving the higher risk populations in greatest need for such programs is laudable and very much in keeping with a theory that got its start in clinical observations (Bowlby, 1951). Such work is likewise important in light of its potential to improve our basic science via enhanced causal inferences, at least when implemented using robust experimental designs (i.e., randomized control trials).

The research featured in this Special Issue clearly pushes the boundaries of the status quo of attachment-based intervention in a number of potentially generative ways. Three of the reports find efficacy of attachment-related intervention not merely for interpersonal outcomes (as might be expected) but for improving aspects of cognitive development (Cassidy et al., 2017; Dubois-Comtois et al., 2017; Lind, Raby, Caron, Roben, \& Dozier, 2017). Another interesting report based on a French sample hones in on some of the specific interpersonal behavioral change mechanisms (i.e., improvements in disrupted maternal communication) by which attachmentinformed home visitations offset risk for disorganized attachment (Tereno et al., 2017). Yet another paper reports that children abandoned in Romania but subsequently randomized to high-quality foster care (compared to children who experienced care as usual) showed fewer signs of reactive attachment disorder and disinhibited social engagement years later (around age 12 years; Humphreys et al., 2017).

That said, the intervention studies presented in this Special Issue also suggest that there is a good deal of progress yet to be made in this area. One broad issue that would benefit from additional attention in future intervention work of this kind is that of study design. First, even the largest interventions reported in this Special Issue (e.g., Cassidy et al., 2017; Humphreys et al., 2017; Lind et al., 2017) consisted of fewer than 200 participants, with adequate power to detect only medium or larger population effects. In contrast, many of the studies reported here included approximately 100 participants, and a handful of "proof of concept" reports were based on fewer than 50 individuals (e.g., Dubois-Comtois et al., 2017; Schact et al., 2017; Swain et al., 2017). Intervention research presents inherent challenges and is immensely expensive and time consuming, but the point remains that only large sample trials are capable of detecting the kinds of small (though ideally enduring) differences between intervention and control groups that might be reasonably expected in this area. Equally important, small sample interventions, combined with a large numbers of potential outcome variables that might be exam- 
ined, create excessive risk for Type 1 errors. In short, if we are to be well positioned to produce replicable answers to important questions about to what extent attachment interventions work, sample sizes in future intervention studies will need to reflect the statistical power requirements necessary to produce relatively precise estimates of focal effects, or else we risk false discovery.

Second, those who read this Special Issue will note a great deal of variability in the kinds of specific attachment-relevant intervention strategies deployed across reports, ranging from interpersonal psychotherapy administered to depressed mothers (Handley et al., 2017) to home visitation (Tereno et al., 2017) to attachment-based video feedback (Dubois-Comtois et al., 2017) to a wide range of manualized yet distinct attachment intervention programs, including the Attachment and Biobehavioral Catch-up for Toddlers Intervention (Lind et al., 2017), the Circle of Security Parenting Intervention (Cassidy et al., 2017), and Mothering From the Inside Out (Suchman et al., 2017). Indeed, there were as many distinct approaches to attachment-related intervention reported in this Special Issue as there were laboratories that contributed intervention data.

Of course, much of the variation just mentioned reflects intentional efforts to optimally meet the distinct needs of the atrisk groups that are the focus of the various intervention efforts described in this issue (e.g., Humphreys et al., 2017). Nonetheless, developing a cumulative science in this area will require that we continue to identify which of these approaches

\section{References}

Bailey, H. N., Tarabulsy, G. M., Moran, G., Pederson, D. R., \& Bento, S. (2017). New insight on intergenerational attachment from a relationship-based analysis. Development and Psychopathology, 29, 443-448.

Bakermans-Kranenburg, M. J., van IJzendoorn, M. H., \& Juffer, F. (2003). Less is more: Meta-analyses of sensitivity and attachment interventions in early childhood. Psychological Bulletin, 129, 195-215.

Blaze, J., \& Roth, T. L. (2017). Caregiver maltreatment causes altered neuronal DNA methylation in female rodents. Development and Psychopathology, 29, 477-489.

Booth-LaForce, C., \& Roisman, G. I. (Eds.). (2014). The Adult Attachment Interview: Psychometrics, stability and change from infancy, and developmental origins. Monographs of the Society for Research in Child Development, 79(3, Serial No. 314), 1-185.

Bowlby, J. (1951). Maternal care and mental health. Geneva: World Health Organization.

Cassidy, J., Brett, B. E., Gross, J. T., Stern, J. A., Martin, D. R., Mohr, J. J., \& Woodhouse, S. S. (2017). Circle of Security-Parenting: A randomized controlled trial in Head Start. Development and Psychopathology, 29, 651-673.

Cicchetti, D. (1984). The emergence of developmental psychopathology. Child Development, 55, 1-7.

Crowell, J. A., \& Owens, G. (1996). Current Relationship Interview and scoring system. Unpublished manuscript, State University of New York at Stony Brook.

Dubois-Comtois, K., Cyr, C., Tarabulsy, G. M., St.-Laurent, D., Bernier, A., $\&$ Moss, E. (2017). Testing the limits: Extending attachment-based intervention effects to infant cognitive outcome and parental stress. Development and Psychopathology, 29, 565-574.

Fearon, R. M. P., Tomlinson, M., Kumsta, R., Skeen, S., Murray, L., Cooper, P. J., \& Morgan, B. (2017). Poverty, early care, and stress reactivity in adolescence: Findings from a prospective, longitudinal study in a low-middle income country. Development and Psychopathology, 29, 449-464.

Fraley, R. C., \& Roisman, G. I. (2014). Categories or dimensions? A taxometric analysis of the Adult Attachment Interview. Monographs of the Society for Research in Child Development, 79(3, Serial No. 314), 36-50. to attachment-related intervention are uniquely efficacious, and for whom (Bakermans-Kranenburg, van IJzendoorn, \& Juffer, 2003). These are nontrivial questions, particularly given the null effects reported in at least one of the larger trials published in the Special Issue (Cassidy et al., 2017). One potentially productive way forward is for researchers in this area to not only include active (nonattachment focused) control groups in their intervention studies (see, e.g., Lind et al., 2017; and Suchman et al., 2017, for excellent examples of this practice) but also to commit to collaborative, large sample trials that directly compare the efficacy of some of the most well-developed attachment interventions now available. Such work will require a great deal of cooperation among investigators, but also has great potential to most efficiently discover how best to improve the lives of children and adults via attachment-related intervention.

\section{Conclusion}

On the multiple fronts just described, the papers contained in this Special Issue have significant potential to help make the next decades of attachment scholarship as productive as the many that have preceded it. Thus, we thank not only the scholars who made this Special Issue possible via their intellectual curiosity, creativity, and hard work but also the participants who, despite the challenges they face in their daily lives, made these reports possible.

George, C., Kaplan, N., \& Main, M. (1984-1996). Adult Attachment Interview protocol. Unpublished manuscript, University of California, Berkeley, CA.

Groh, A. M., Fearon, R. P., van IJzendoorn, M., Bakermans-Kranenburg, M., \& Roisman, G. I. (in press). Attachment in the early life course: Metaanalytic evidence for its role in socio-emotional development. Child Development Perspectives.

Grossmann, K. E., Grossmann, K., \& Waters, E. (Eds.). (2005). Attachment from infancy to adulthood: The major longitudinal studies. New York: Guilford Press.

Guild, D. J., Toth, S. L., Handley, E. D., Rogosch, F. A., \& Cicchetti, D. (2017). Attachment security mediates the longitudinal association between child-parent psychotherapy and peer relations for toddlers of depressed mothers. Development and Psychopathology, 29, 587-600.

Handley, E. D., Michl-Petzing, L. C., Rogosch, F. A., Cicchetti, D., \& Toth, S. L. (2017). Developmental cascade effects of interpersonal psychotherapy for depressed mothers: Longitudinal associations with toddler attachment, temperament, and maternal parenting efficacy. Development and Psychopathology, 29, 601-615.

Humphreys, K. L., Nelson, C. A., Fox, N. A., \& Zeanah, C. H. (2017). Signs of reactive attachment disorder and disinhibited social engagement disorder at age 12 years: Effects of institutional care history and high-quality foster care. Development and Psychopathology, 29, 677-686.

Kobak, R., Zajac, K., Abbott, C., Zisk, A., \& Bounoua, N. (2017). Atypical dimensions of caregiver-adolescent interaction in an economically disadvantaged sample. Development and Psychopathology, 29, 405416.

Lind, T., Raby, K. L., Caron, E. B., Roben, C. K. P., \& Dozier, M. (2017). Enhancing executive functioning among toddlers in foster care with an attachment-based intervention. Development and Psychopathology, 29, 575-586.

Main, M., \& Goldwyn, R. (1984-1998). Adult attachment scoring and classification system. Unpublished manuscript, University of California, Berkeley. 
Main, M., Goldwyn, R., \& Hesse, E. (2003-2008). Adult attachment scoring and classification system. Unpublished manuscript, University of California, Berkeley.

Martin, J., Bureau, J.-F., Lafontaine, M.-F., Cloutier, P., Hsiao, C., Pallanca, D., \& Meinz, P. (2017). Preoccupied but not dismissing attachment states of mind are associated with nonsuicidal self-injury. Development and Psychopathology, 29, 379-388.

Martin, M. J., Sturge-Apple, M. L., Davies, P. T., Romero, C. V., \& Buckholz, A. (2017). A process model of the implications of spillover from coparenting conflicts into the parent-child attachment relationship in adolescence. Development and Psychopathology, 29, 417-431.

Mulder, R. H., Rijlaarsdam, J., Luijk, M. P. C. M., Verhulst, F. C., Felix, J. F., Tiemeier, H., . . . van IJzendoorn, M. H. (2017). Methylation matters: FK506 binding protein 51 (FKBP5) methylation moderates the associations of $F K B P 5$ genotype and resistant attachment with stress regulation. Development and Psychopathology, 29, 491-503.

Poehlmann-Tynan, J., Burnson, C., Runion, H., \& Weymouth, L. A. (2017). Attachment in young children with incarcerated fathers. Development and Psychopathology, 29, 389-404.

Quevedo, K., Waters, T. E. A., Scott, H., Roisman, G. I., Shaw, D. S., \& Forbes, E. E. (2017). Brain activity and infant attachment history in young men during loss and reward processing. Development and Psychopathology, 29, 465-476.

Raby, K. L., Labella, M. H., Martin, J., Carlson, E. A., \& Roisman, G. I. (2017). Childhood abuse and neglect and insecure attachment states of mind in adulthood: Prospective, longitudinal evidence from a high-risk sample. Development and Psychopathology, 29, 347-363.

Raby, K. L., Yarger, H. A., Lind, T., Fraley, R. C., Leerkes, E., \& Dozier, M. (2017). Attachment states of mind among internationally adoptive and foster parents. Development and Psychopathology, 29, 365-378.

Roisman, G. I., \& Booth-LaForce, C. (2014). General Discussion. Monographs of the Society for Research in Child Development, 79(3, Serial No. 314), 126-137.

Roisman, G. I., Fraley, R. C., \& Belsky, J. (2007). A taxometric study of the Adult Attachment Interview. Developmental Psychology, 43, 675-686.

Roisman, G. I., Fraley, R. C., \& Booth-LaForce, C. (2014). Pulling ourselves up by our bootstraps: A rejoinder to Van IJzendoorn and Bakermans-Kranenburg (2014). Monographs of the Society for Research in Child Development, 79(3, Serial No. 314), 168-173.
Roisman, G. I., Rogosch, F. A., Cicchetti, D., Groh, A. M., Haltigan, J. D., Haydon, K. C., Holland, A. S., \& Steele, R. D. (2017). Attachment states of mind and inferred childhood experiences in maltreated and comparison adolescents from low-income families. Development and Psychopathology, 29, 337-345.

Schacht, R., Meins, E., Fernyhough, C., Centifanti, L. C. M., Bureau, J.-F., \& Pawlby, S. (2017). Proof of concept of a mind-mindedness intervention for mothers hospitalized for severe mental illness. Development and Psychopathology, 29, 555-564.

Sroufe, L. A., Egeland, B., Carlson, E. A., \& Collins, W. A. (2005). The development of the person: The Minnesota Study of Risk and Adaptation from Birth to Adulthood. New York: Guilford Press.

Suchman, N. E., DeCoste, C. L., McMahon, T. J., Dalton, R., Mayes, L. C., \& Borelli, J. (2017). Mothering From the Inside Out: Results of a second randomized clinical trial testing a mentalization-based intervention for mothers in addiction treatment. Development and Psychopathology, 29, 617-636.

Swain, J. E., Ho, S. S., Rosenblum, K. L., Morelen, D., Dayton, C. J., \& Muzik, M. (2017). Parent-child intervention decreases stress and increases maternal brain activity and connectivity during own baby-cry: An exploratory study. Development and Psychopathology, 29, 535-553.

Tereno, S., Madigan, S., Lyons-Ruth, K., Plamondon, A., Atkinson, L., Guedeney, N., . . . Guedeney, A. (2017). Assessing a change mechanism in a randomized home-visiting trial: Reducing disrupted maternal communication decreases infant disorganization. Development and Psychopathology, 29, 637-649.

Thijssen, S., Muetzel, R. L., Bakermans-Kranenburg, M. J., Jaddoe, V. W. V., Tiemeier, H., Verhulst, F. C., . . . van IJzendoorn, M. H. (2017). Insensitive parenting may accelerate the development of the amygdala-medial prefrontal cortex circuit. Development and Psychopathology, 29, 505-518.

van IJzendoorn, M. H., \& Bakermans-Kranenburg, M. J. (2014). Confined quest for continuity: The categorical versus continuous nature of attachment. Monographs of the Society for Research in Child Development, 79(3, Serial No. 314), 157-167.

VanTieghem, M. R., Gabard-Durnam, L., Goff, B., Flannery, J., Humphreys, K. L., Telzer, E. H., . . . Tottenham, N. (2017). Positive valence bias and parent-child relationship security moderate the association between early institutional caregiving and internalizing symptoms. Development and Psychopathology, 29, 519-533. 